\title{
US preexposures retard excitatory and facilitate inhibitory conditioning of the rabbit's nictitating membrane response
}

\author{
MICHAEL E. SALADIN and ROBERT W. TAIT \\ University of Manitoba, Winnipeg, Manitoba, Canada
}

\begin{abstract}
Two experiments were conducted to examine the effects of US preexposure on differential conditioning of the rabbit's nictitating membrane response. Both experiments consisted of three phases: a 10-day US preexposure phase, a 7-day differential conditioning phase, and a 3-day retardation of learning test for inhibition. In Experiment 1, US preexposures retarded the development of excitation to $\mathrm{CS}^{+}$but facilitated the development of inhibition to $\mathrm{CS}^{-}$. In Experiment 2, half of the preexposed subjects received the preexposures in one experimental environment and differential conditioning in a second environment. The remaining preexposed subjects received both phases in a single environment. Retarded excitatory and facilitated inhibitory conditioning were observed only in the preexposed subjects that received both phases in the same environment. Rabbits that received a context shift performed at control levels. The results are discussed in terms of current theories of US preexposure effects, and the best account was provided by a modified associative theory.
\end{abstract}

Explanatory models of the observation that preconditioning exposure to a US reliably retards subsequent discrete trial acquisition involving that US have taken two forms (see Randich \& LoLordo, 1979). In general, models invoke either nonassociative or associative mechanisms (Baker, Mercier, Gabel, \& Baker, 1981; Hinson, 1982; Randich \& LoLordo, 1979). Nonassociative models emphasize the effects of US preexposure on US-UR reactions, whereas associative models focus on changes in the processing of discrete signals that result when a US is presented alone.

Two nonassociative models have been posited. Adaptational accounts (Macdonald, 1946; Taylor, 1956) maintain that pretreatment exposure to a US reduces the subject's responsiveness to the US. With the weakening of the US-UR reaction, the US becomes less functional, and hence subsequent conditioning proceeds at a slower rate. On the other hand, opponent-process models (LoLordo \& Randich, 1981; Solomon \& Corbit, 1974) postulate that preconditioning experience with a US leads to the development of a secondary endogenous hedonic process which opposes the primary hedonic consequence elicited by the US. The integration over time of the two opponent processes has the consequence of reducing the net hedonic effectiveness of the US and thereby retarding ensuing excitatory conditioning.

Associative models also take two general forms. Cognitive theories assert that during the US preexposure

This research was supported by Grant A0312 from the Natural Sciences and Engineering Research Council of Canada to R. W. Tait. Requests for reprints should be addressed to: R. W. Tait, Psychology Department, University of Manitoba, Winnipeg, Manitoba, Canada R3T 2N2. phase, subjects learn something about US occurrence that produces a change in the "processing" of the US. Subjects may learn to ignore the US (Mackintosh, 1975), that the US is irrelevant (Mackintosh, 1973), or that the US is neither predictable nor controllable (Baker et al., 1981; Maier \& Seligman, 1976). Whatever the mechanism, the initial learning about US occurrence is thought to interfere proactively with the acquisition of subsequent CSUS relationships (Baker et al., 1981). In contrast, the context blocking (Mis \& Moore, 1973; Randich \& LoLordo, 1979; Tomie, 1976; Tomie, Murphy, Fath, \& Jackson, 1980) and scalar expectancy (Gibbon \& Balsam, 1981) accounts assert that during US preexposures, the context becomes a signal for the occurrence of the US. The context blocking model posits that the presentation of an unsignaled US in a context results in an excitatory association between the context and the US. Subsequently, when a discrete signal for the US is introduced into the context, the discrete CS competes with the context for the associative strength that the US supports (Rescorla \& Wagner, 1972). If sufficient US preexposures have occurred, then the context will have acquired the majority of the associative strength. As a consequence, the context "blocks" (Kamin, 1968, 1969) the development of associative strength to the discrete CS and retarded acquisition will be observed. Although the contextual blocking account asserts that US preexposure exerts its influence by retarding the development of associative strength, scalar expectancy theory (Gibbon \& Balsam, 1981) argues that performance, not learning, is interfered with by the contextual conditioning that occurs during US preexposures. For scalar expectancy theory, performance to a discrete CS occurs only if the CS generates a greater expectancy of US occurrence than does the context. Since 
US preexposures are thought to result in a high level of expectancy for the US in the context, a large number of CS-US pairings would be required to produce a greater US expectancy to the CS. Hence, retarded CR performance would be observed after US preexposures.

Although all models predict that excitatory conditioning is retarded after US preexposures, differences emerge in their predictions regarding the effects of US preexposure on subsequent inhibitory conditioning. Since the adaptational accounts assert that the effectiveness of the US is reduced by US preexposures and the cognitive accounts indicate that processing of the US is reduced, both models predict that the US'S capacity to reinforce all CSUS relationships would be degraded. Accordingly, acquisition of inhibitory as well as excitatory processes should be retarded by US preexposures.

Conversely, opponent-process, context blocking, and scalar expectancy theories would expect, albeit by different mechanisms, facilitated inhibitory acquisition following US preexposures. For opponent-process theory, inhibitory conditioning results if a CS is paired with the US's hedonically opposite process (Solomon \& Corbit, 1974). Since the US's hedonically opposite process is believed to be strengthened during US preexposures, US-preexposed subjects should have stronger hedonic opposites than nonpreexposed subjects, and therefore should acquire inhibition more rapidly. For the context blocking model, an extension of the analogy to the Rescorla-Wagner theory would be the adoption of the theory's necessary conditions for the establishment of associative inhibition: the occurrence of a discrete stimulus in the absence of the US in a context that has an excitatory association with the US (Wagner \& Rescorla, 1972). If US preexposures produce an excitatory context (Randich \& LoLordo, 1979; Tomie et al., 1980), then US-preexposed subjects would commence inhibitory conditioning in an already excitatory context whereas nonpreexposed subjects would begin in a neutral context. Facilitated inhibitory conditioning should result for the preexposed subjects. A similar argument can be advanced from scalar expectancy theory. If inhibition results when the expectation of the US in the presence of a CS is much lower than the US expectation in the context, then preexposed subjects that have established an expectancy of the US in the context should acquire inhibition more rapidly than nonpreexposed subjects which initially lack this expectancy.

Hinson (1982, Experiment 4) provided the initial delineation of the effects of US preexposure on inhibitory conditioning. Hinson found that backward conditioning of the rabbit's eyelid response was more inhibitory if the backward conditioning was preceded by US preexposures. Although Hinson (1982) interpreted his results as being most consistent with the context blocking model, the results are also consistent with both scalar expectancy and opponent-process models. In particular, the use of backward conditioning would be optimal from an opponent-process perspective, since the backward CS oc- curs near the expected temporal maximum strength of the US's hedonically opposite process.

The purpose of Experiment 1 was to confirm Hinson's (1982) observation that US preexposure facilitates subsequent inhibitory conditioning and to extend his observation to a second inhibitory conditioning paradigm, differential conditioning (Moore, 1972; Pavlov, 1927; Reberg \& Black, 1969; Wessels, 1973). Experiment 2 examined the effect of a context shift between the US preexposure phase and the inhibitory conditioning phase. If facilitated inhibition results from associative processes involving the context, then a shift in context should eliminate the facilitation of inhibition. On the other hand, if facilitated inhibition results from an enhanced hedonic opposite, the shift in context should have no effect.

\section{EXPERIMENT 1}

If a common process during US preexposures is responsible for both retarded excitatory (Randich \& LoLordo, 1979) and facilitated inhibitory (Hinson, 1982) conditioning, then the simultaneous occurrence of both effects should be observed in the same subject. Experiment 1 was designed to identify both effects by employing differential conditioning of the rabbit's nictitating membrane response. The effects of US preexposure on excitatory conditioning were measured by monitoring $\mathrm{CRs}$ on $\mathrm{CS}^{+}-$ US trials. The effects of US preexposure on inhibitory conditioning were measured by monitoring the responding to $\mathrm{CS}^{-}$and, after the differential conditioning phase was completed, by applying a retardation of learning test for inhibition. A group that received only differential conditioning was included to detect the effects of US preexposure, and a novel CS control group was included to confirm that inhibition was acquired.

The selection of the retardation of learning test was made on the basis of Williams and Tait's (1983) observation that differential conditioning of the rabbit's nictitating membrane response using tone, click, or airpuff CSs yielded substantial levels of inhibition when subsequently assessed with either summation or retardation of learning tests. In the present experiment, use of a summation test would require the pairing of a third CS with the US either before or after the US preexposure phase. Either procedure might interact with the processes operating during differential conditioning to mask the effects of US preexposure on acquisition to the $\mathrm{CS}^{+}$and $\mathrm{CS}^{-}$. Accordingly, a retardation of learning test was chosen in order to minimize possible interpretive problems.

\section{Method}

Subjects. Forty-eight naive male and female New Zealand white rabbits, weighing between 2.0 and $3.0 \mathrm{~kg}$, were obtained from the Kleefeld Rabbitry in Tourond, Manitoba. All subjects were housed in separate $60 \times 45 \mathrm{~cm}$ wire-mesh cages and were given free access to food and water.

Apparatus. Conditioning of the rabbit's nictitating membrane response was conducted in an apparatus that has been described 
elsewhere (Gormezano, 1966). Each subject was placed in a Plexiglas restraining box; the head was fixed in position by foam pinnae clamps; the right eyelids were held open by Newey tailor hooks attached to a bipartite Velcro strip that was adjusted to fit securely around the rabbit's head; and a headmount was tightly positioned over the rabbit's snout. The piano-wire armature of a $10 \mathrm{~K}$ microtorque potentiometer that was fixed to the headmount was coupled to a previously implanted $2.0-\mathrm{mm}$ loop of 00 Ethicon suture by means of a staple and thread. The voltage output of each potentiometer was sensed by one of the 16 channels of a 10-bit analog-to-digital converter interface of a Raytheon 703 computer. The restraining box and the transducing apparatus were enclosed in one of eight identical, ventilated, fireproof, legal-size file cabinet chambers. The US was a $2.5-\mathrm{mA}, 100-\mathrm{msec}, 60-\mathrm{Hz}$ constant current shock delivered to two stainless steel 9-mm Autoclips implanted $10 \mathrm{~mm}$ behind and $10 \mathrm{~mm}$ above and below the horizontal plane of the right eye. The $\mathrm{CS}^{+}$was a 600 -msec, 20-psi airpuff delivered through a blunted 16-ga needle that was fixed approximately $3.0 \mathrm{~cm}$ from the animal's left abdominal region. The $\mathrm{CS}^{-}$was a $600-\mathrm{msec}, 80-\mathrm{dB}$, $10-\mathrm{Hz}$ click delivered through an $8-\Omega$ speaker located directly in front of the subject. Continuous masking white noise was presented in the experimental chamber at $72 \mathrm{~dB}$. A software system, modified from Tait and Gormezano (1974) and implemented on a $8 \mathrm{~K}$ Raytheon 703 computer, controlled the delivery of the stimuli and the recording of responses.

Procedure. Two days after arrival, a 2.0-mm loop of suture was implanted in the nictitating membrane of each rabbit's right eye. Two days following surgery, the subjects were assigned randomly to one of three groups (Groups UD, D, and E). On the 10 days that followed, Group UD received 10 sessions of US preexposure, while Groups D and E were left undisturbed in their home cages. In each US preexposure session, 20 shock USs were presented with a mean intertrial interval of $3.0 \mathrm{~min}$. The differential conditioning phase commenced on the 11th day, and consisted of seven daily sessions. In each session, Groups UD and D received $20 \mathrm{CS}^{+}$-US (airpuff-shock) trials randomly interspersed with $20 \mathrm{CS}^{-}$(click) trials. The sequencing and timing of the trial types were identical for both groups. Group $\mathrm{E}$ received only excitatory training, which consisted of $20 \mathrm{CS}^{+}$-US (airpuff-shock) pairings randomly intercalated with 20 observation trials in which the animal was monitored for responding during a 500-msec interval. Group E's paired trials were temporally matched to the paired trials of Groups UD and D; Group E's observation trials were temporally matched to the $\mathrm{CS}^{-}$trials of the other two groups. Group E was included to assess the level of inhibition measured with the retardation of learning test. On the day following the last differential conditioning session, all subjects received a retardation of learning test. The test consisted of three daily sessions of excitatory conditioning in which 20 paired $\mathrm{CS}^{-}$-US (click-shock) trials were given per session. Throughout the experiment, the mean intertrial interval was $3.0 \mathrm{~min}$. In addition, all paired trials had CS onset precede US onset by $500 \mathrm{msec}$.

Initially, 16 subjects were assigned to each of the above groups. However, one subject in each of Groups UD and D was removed from the experiment due to illness. Thus, Groups UD, D, and E contained 15,15 , and 16 subjects, respectively.

Nictitating membrane responses were scored during the 500 -msec interval following the onset of either the $\mathrm{CS}^{+}$or the $\mathrm{CS}^{-}$and during an equivalent 500 -msec period on observation trials. The criterion for a CR or UR was set at $1 \mathrm{~mm}$ of movement of the nictitating membrane response during the CS or US, respectively. In both cases, $1 \mathrm{~mm}$ of movement of the nictitating membrane corresponded to a change of $0.2 \mathrm{~V}$ in the analog-to-digital conversion system. During the US preexposure phase, the maximum amplitude (i.e., the largest change from the pre-US baseline voltage input to the analog-to-digital converter that occurred in a 500-msec interval following US onset) of the UR was recorded for Group UD.

\section{Results and Discussion}

Preexposure phase. Figure 1 displays the mean UR topography of Group UD on Days 1, 5, and 10 of the US preexposure phase. The figure suggests that URs increased

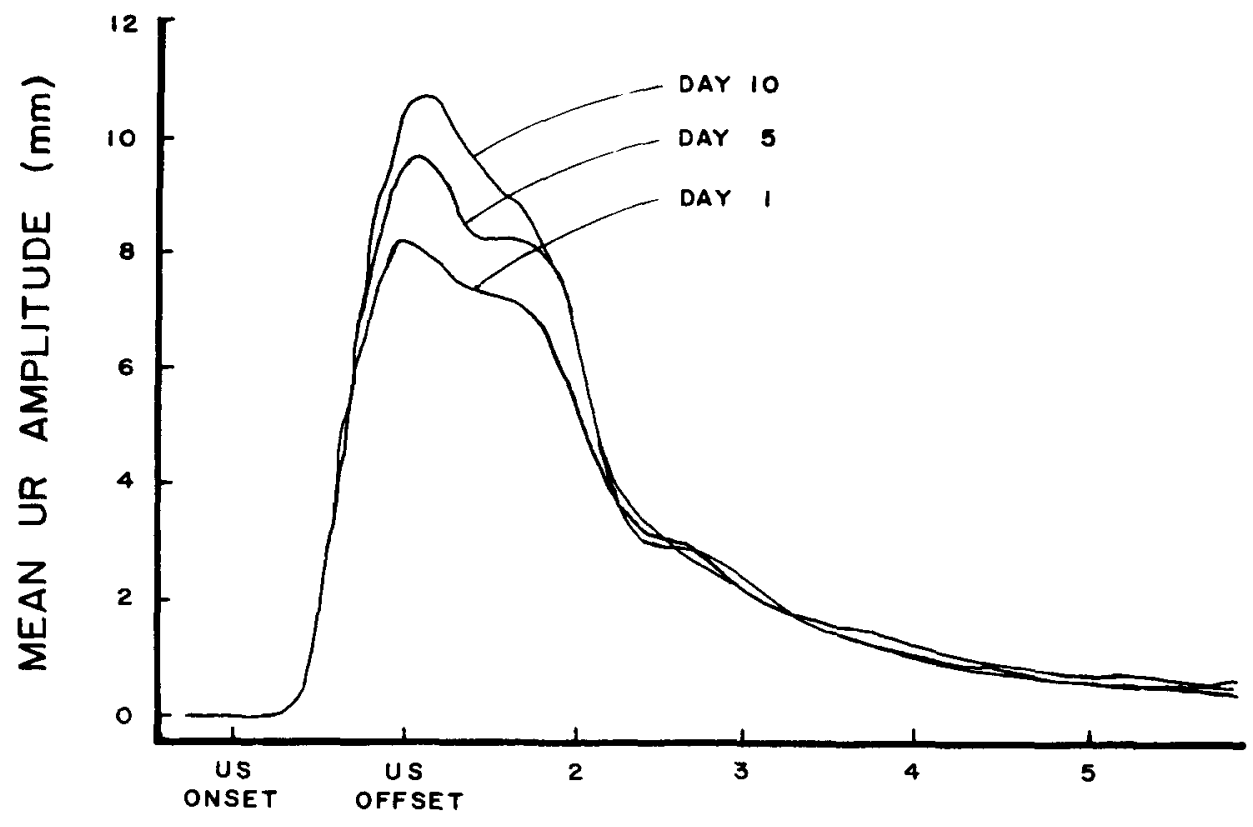

TIME (100 msec)

Figure 1. The mean UR topography for Group UD on Days 1, 5, and 10 of the US preexposure phase. The time base is initialized at US onset. 
in size over the US preexposure phase. A repeated measures ANOVA applied to the daily mean UR amplitude of each subject confirmed the graphical interpretation by revealing a significant days main effect $[F(9,126)=2.35$, $p<.05$ ]. Orthogonal components for trend applied to the days effect contained only a significantly increasing linear component $[F(1,14)=8.85, p<.05]$. Thus, the statistical analysis confirmed that UR amplitude increased over days of US preexposure.

Differential conditioning phase. The mean percentage of $\mathrm{CRs}$ to $\mathrm{CS}^{+}$and $\mathrm{CS}^{-}$over the 7-day differential conditioning phase was 58.5 and 9.8 , respectively. A repeated measures ANOVA identified that the rabbits differentially responded to the airpuff and click by yielding a significant trial-type main effect $[F(1,43)=339.26, p<.01]$. The mean percentages of CRs to $\mathrm{CR}^{+}$for Groups UD, $D$, and $E$ were $47.4,61.5$, and 66.1 , respectively. A mixed-model ANOVA applied to CRs on $\mathrm{CS}^{+}$trials revealed a significant group main effect $[F(2,43)=3.99$, $p<.05]$. Subsequent application of Newman-Keuls tests $(p=.05)$ indicated that the mean percentage of CRs was lower for Group UD than for either Group D or Group E, which did not differ from each other. Thus, the analyses indicated that US preexposure retarded the acquisition of $\mathrm{CRs}$ to $\mathrm{CS}^{+}$. The mean percentages of CRs on $\mathrm{CS}^{-}$trials during differential conditioning were 7.0, 19.9, and 3.2 for Groups UD, D, and E, respectively. A mixed-model ANOVA identified a significant group main effect $[F(2,43)=5.66, p<.05]$. The Newman-Keuls tests confirmed that Group D had a higher mean percentage of CRs to $\mathrm{CS}^{-}$than either Group UD or Group E, which did not differ. Since Group E received no stimuli on $\mathrm{CS}^{-}$ trials and provided an index of baseline responding, the responding of Group UD appeared to be at baseline levels. Therefore, the analyses established that US preexposure reduced $\mathrm{CS}^{-}$responding to approximately baseline levels.

Figure 2 depicts the mean percentage of $\mathrm{CRs}^{+} \mathrm{CS}^{+}$ and $\mathrm{CS}^{-}$as a function of days of differential conditioning for Groups UD, D, and E. For Group E, which did not receive a stimulus on $\mathrm{CS}^{-}$trials, $\mathrm{CS}^{-}$responding indicates the baseline level of responding that was obtained from the corresponding 500-msec interval of the observation trials. Figure 2 shows that on the $\mathrm{CS}^{+}$trials, the initial occurrence of CRs was retarded in Group UD, but, once underway, $\mathrm{CR}$ acquisition occurred at about the same rate and to the same asymptote in Group UD as in Groups D and $E$. The absence of a day $\times$ group interaction $[F(12,258)=1.40]$ is consistent with the apparent parallel acquisition functions. Figure 2 also shows that the mean percentage of CRs to $\mathrm{CS}^{-}$was low and diverged among the groups over the 7 days of differential conditioning. Group D showed a gradual increase in responding to a low asymptotic value, whereas the responding of Groups UD and E were similar and did not systematically change over days. The ANOVA revealed a significant day $\times$ group interaction $[F(12,258)=3.22, p<.01]$, which confirms the divergence in $\mathrm{CS}^{-}$response rates over days. Orthogonal components for trend revealed a significant linear component to the interaction $[F(2,258)=6.65$, $p<.01]$. Orthogonal components for trend applied to each group identified a significant linear increase in responding on $\mathrm{CS}^{-}$trials over days for Group $\mathrm{D}[F(1,258)$

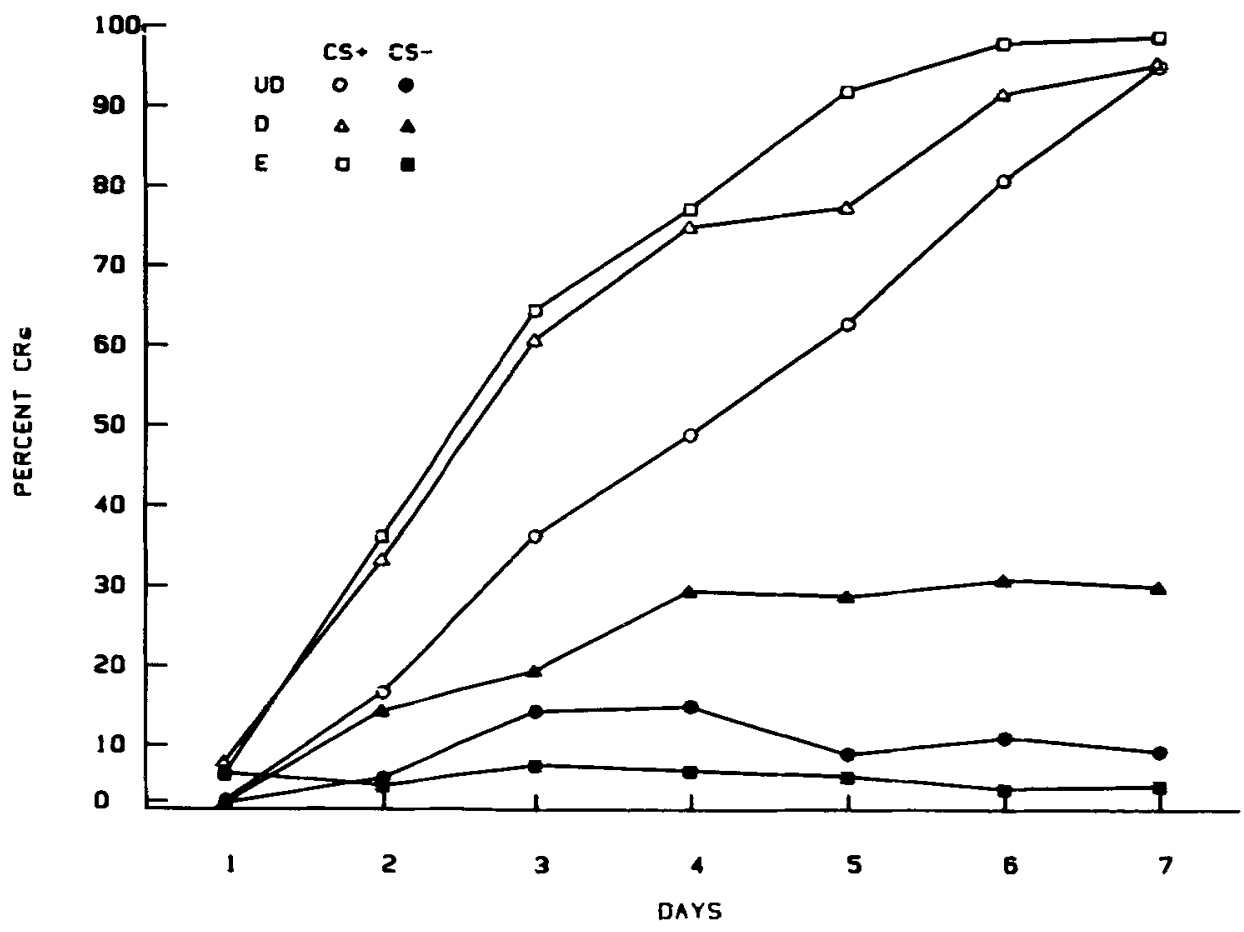

Figure 2. The mean daily percentages of $\mathrm{CRs}$ to $\mathrm{CS}^{+}$and $\mathrm{CS}^{-}$for Groups UD, D, and $\mathrm{E}$ as a function of the 7 days of differential conditioning. 
$=21.65, p<.01]$ but not for Groups UD and E (both $\left.F_{s}<1\right)$. Thus, the statistical analyses confirmed that only Group D exhibited a systematic increase in $\mathrm{CS}^{-}$responding over days.

Retardation of learning test. The mean percentages of CRs that occurred during the retardation of learning inhibition test phase were $60.6,78.5$, and 92.6 for Groups UD, D, and E, respectively. A mixed-model ANOVA yielded a significant group main effect $[F(2,43)=16.30, p<.01]$, which, according to Newman-Keuls tests, resulted from the fact that Groups UD, D, and E all differed from one another. The lower responding in Groups UD and D relative to Group E demonstrated that the differential conditioning produced associative inhibition. The lower performance of Group UD relative to Group D identifies a greater associative inhibition in Group UD. Thus, US preexposure facilitated the development of inhibition.

Figure 3 depicts the mean percentages of CRs for Groups UD, D, and $\mathbf{E}$ as a function of days during the retardation of learning test. The figure shows that Group $\mathrm{E}$ exhibited a high, stable level of responding, indicating a substantial level of transfer from the acquisition phase. In contrast, the percentage of CRs was initially lower for Group D and lowest for Group UD. All groups reached a common asymptote by Day 3 of the test. The pattern of responding over days yielded a significant day $\times$ group interaction $[F(4,86)=8.83, p<.01]$, which contained a significant linear component for trend $[F(2,86)=14.66$, $p<.01]$. Since Group UD contributed $71 \%$ and Group D contributed $25 \%$ of the linear variability, the analysis indicated that Group UD experienced the largest increase in responding over the inhibition test phase, which confirms a greater retardation for Group UD and hence a higher level of associative inhibition.

The slower acquisition on $\mathrm{CS}^{+}$trials during differential conditioning of Group UD relative to Groups D and $E$ indicated that the US preexposures retarded the onset of excitatory conditioning. Thus, Experiment 1 confirmed previous findings of US-preexposure-produced retardation of nictitating membrane (Mis \& Moore, 1973) and eyelid (Hinson, 1982; Siegal \& Domjan, 1971) conditioning in the rabbit. Furthermore, since Group UD had lower response levels to the $\mathrm{CS}^{-}$and slower acquisition during the retardation of learning test for inhibition than Group D, Group UD's CS- was more inhibitory than was that of Group D. Thus, US preexposures facilitated the acquisition of associative inhibition during differential conditioning, providing converging evidence for Hinson's (1982) finding with backward conditioning.

The observation that US preexposures simultaneously produce both retarded excitatory and facilitated inhibitory conditioning suggests that a common process is acting to produce both effects. Of the models advanced to account for US preexposure phenomena, only opponent process (LoLordo \& Randich, 1981; Solomon \& Corbit, 1974), context blocking (Randich \& LoLordo, 1979; Tomie et al., 1980), and scalar expectancy (Gibbon $\&$ Balsam, 1981) theories have the potential to yield both effects. The present results, like those of Hinson (1982, Experiment 4) are consistent with each of these accounts. However, since context blocking and scalar expectancy theories invoke

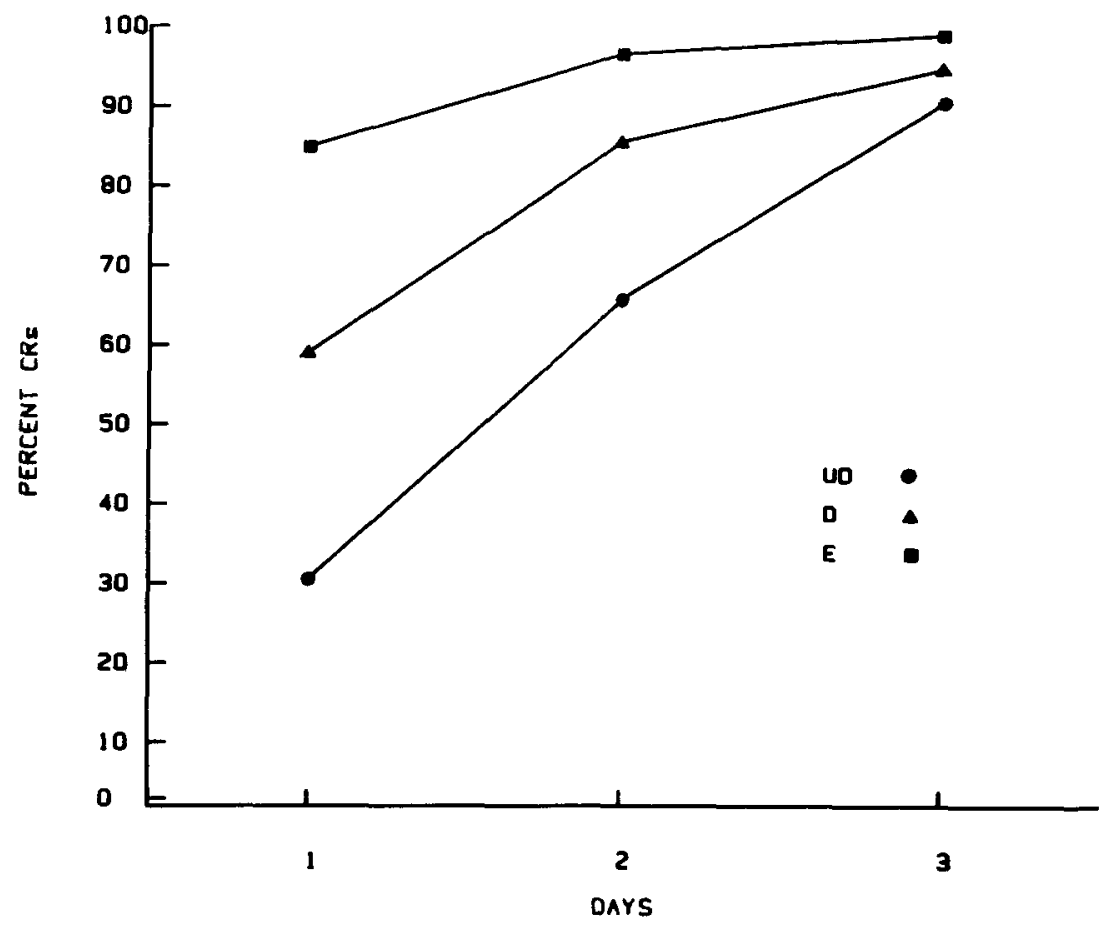

Figure 3. The mean daily percentages of CRs during the 3-day retardation of learning test of inhibition for Groups UD, D, and E. 
an association between the context and the US to explain retarded excitatory and facilitated inhibitory conditioning, the associative theories would expect the elimination of both effects by a change of experimental environment after a US preexposure phase. On the other hand, since opponent-process theory relies on changes in the consequences of the US to produce both effects, a context shift inserted after US preexposures should not alter the USpreexposure effects.

\section{EXPERIMENT 2}

Since a context shift after US preexposures removes the deleterious effects of US preexposure on excitatory conditioning (Baker \& Mercier, 1982; Hinson, 1982, Experiment 1; Tomie et al., 1980; Willner, 1978), the removal of the facilitation effect on inhibitory conditioning would be expected if a common process produces both effects. Such an observation would be strong evidence for the two associative theories. To test this prediction, Experiment 1 was replicated with the inclusion of a second preexposed group that received a context shift between the US preexposure phase and the differential conditioning phase.

\section{Method}

Subjects. Forty-eight naive male and female New Zealand white rabbits, weighing between 2.5 and $3.0 \mathrm{~kg}$, served as subjects.

Apparatus. The apparatus was identical to that described earlier for Experiment 1, with the following exceptions. US preexposures were administered in one of two distinctly different apparatuses (i.e., contexts). One of the apparatuses was the same as that described in Experiment 1 (designated NM1 apparatus); the other was an apparatus that was originally constructed for conditioning of the legflexion response (Quesnel, 1983) in the rabbit (designated NM2 apparatus) but was modified for nictitating membrane conditioning in the present experiment. The NM2 apparatus consisted of six experimental chambers in a room with continuous white noise, which acoustically isolated the subjects from the computer and data processing equipment located in an adjacent room. Each of the six adjoining experimental chambers was constructed of $1 / 2$-in. white plywood boards and measured $75 \mathrm{~cm}$ long, $33 \mathrm{~cm}$ wide, and $85 \mathrm{~cm}$ high. The restraining boxes were similar to those described elsewhere by Gormezano (1966) with the exception that they were constructed of wood rather than Plexiglas. The restraining boxes were locked onto support stands and placed in separate, visually isolated chambers. Unlike the NM1 apparatus described earlier, the NM2 apparatus provided the subjects with a complete view of the experimental room, since there were no doors on the individual chambers. In addition, illumination for the chambers was provided by the ambient lighting in the experimental room.

Procedure. Surgical preparation, recovery, and group assignment procedures were the same as those employed in Experiment 1. Moreover, the experimental protocol and parameters were identical to those employed in Experiment 1. The criterion for CRs and URs were also the same.

Two groups (Groups UD-S and UD-D) received 10 sessions of shock US preexposures. However, Group UD-S received the preexposure sessions in the NM1 apparatus and Group UD-D received the preexposures in the NM2 apparatus. The two remaining groups (Groups D and E) were left undisturbed in their home cages throughout the preexposure phase. The 7 days of differential conditioning were conducted in the NM1 apparatus for all groups. Thus, differen- tial conditioning occurred in the same apparatus as did the US preexposures for Group UD-S but in a different apparatus for Group UD-D. As in Experiment 1, Group D received differential conditioning and Group $\mathrm{E}$ received only the $\mathrm{CS}^{+}$-US pairings. Finally, all groups received a 3-day retardation of learning test in the same context in which they received their differential training.

Originally, 12 subjects were assigned to each of the four designated groups. However, 1 subject in each of Groups UD-S and D had to be discarded due to illness. Thus, Groups UD-D, UD-S, $\mathrm{D}$, and $\mathrm{E}$ contained $12,11,11$, and 12 subjects, respectively.

\section{Results and Discussion}

US preexposure phase. Figure 4 presents the mean UR topography for Groups UD-S (top frame) and UD-D (bottom frame) on Days 1, 5, and 10 of the US preexposure phase. The figure suggests that both groups showed an increase in UR amplitudes over days. A repeated measures ANOVA applied to the daily mean UR amplitude revealed a significant days main effect $[F(9,189)=13.83$, $p<.01]$, and orthogonal components for trend contained only a significant linear component $[F(1,21)=82.71$, $p<.01]$. There were no observed group differences $[F(1,21)=1.65]$ and no days $\times$ group interaction $[F(9,189)=1.02]$. Thus, the analysis confirms that UR amplitudes increased over the 10 days of US preexposure.

Differential conditioning phase. The mean percentages of $\mathrm{CRs}^{2} \mathrm{CS}^{+}$and $\mathrm{CS}^{-}$during differential conditioning were 61.6 and 5.8, respectively. A repeated measures ANOVA confirmed that $\mathrm{CS}^{+}$responding was higher than $\mathrm{CS}^{-}$responding $[F(1,42)=656.85, p<.01]$. The mean percentages of $\mathrm{CRs}$ to $\mathrm{CS}^{+}$during differential conditioning were 43.7, 63.7, 69.0, and 69.1 for Groups UD-S, UD-D, D, and E, respectively. A mixed-model ANOVA applied to the $\mathrm{CS}^{+}$data for all groups revealed a significant group main effect $[F(3,42)=7.22, p<.01]$. Newman-Keuls tests indicated that the percentage of CRs was lower for Group UD-S than for each of the remaining groups, which did not differ from each other. Thus, the analyses indicated that US preexposure retarded subsequent excitatory conditioning if the conditioning occurred in the same context, but not if it occurred in a different context. The mean percentages of CRs to $\mathrm{CS}^{-}$ were 2.6, 9.0, 11.1, and 0.9 for Groups UD-S, UD-D, $D$, and E, respectively. Again, a mixed-model ANOVA revealed a significant group main effect $[F(3,42)=6.03$, $p<.01]$. The Newman-Keuls tests indicated that the percentages of responding were higher for Groups UD-D and $D$, which did not differ from one another, than for Groups UD-S and E, which also did not differ from one another. Thus, preexposures decreased responding on $\mathrm{CS}^{-}$trials only if the $\mathrm{CS}^{-}$trials occurred in the same context as the US preexposures.

Figure 5 depicts the mean percentage of $\mathrm{CRs}$ for $\mathrm{CS}^{+}$ and $\mathrm{CS}^{-}$trials as a function of days of differential conditioning for Groups UD-D, UD-S, D, and E. Response levels from the observation trials of Group $E$ are included as a baseline level for $\mathrm{CS}^{-}$responding in the other groups. The figure reveals that responding to $\mathrm{CS}^{+}$was characterized by a steady increase over days to high asymptotic 


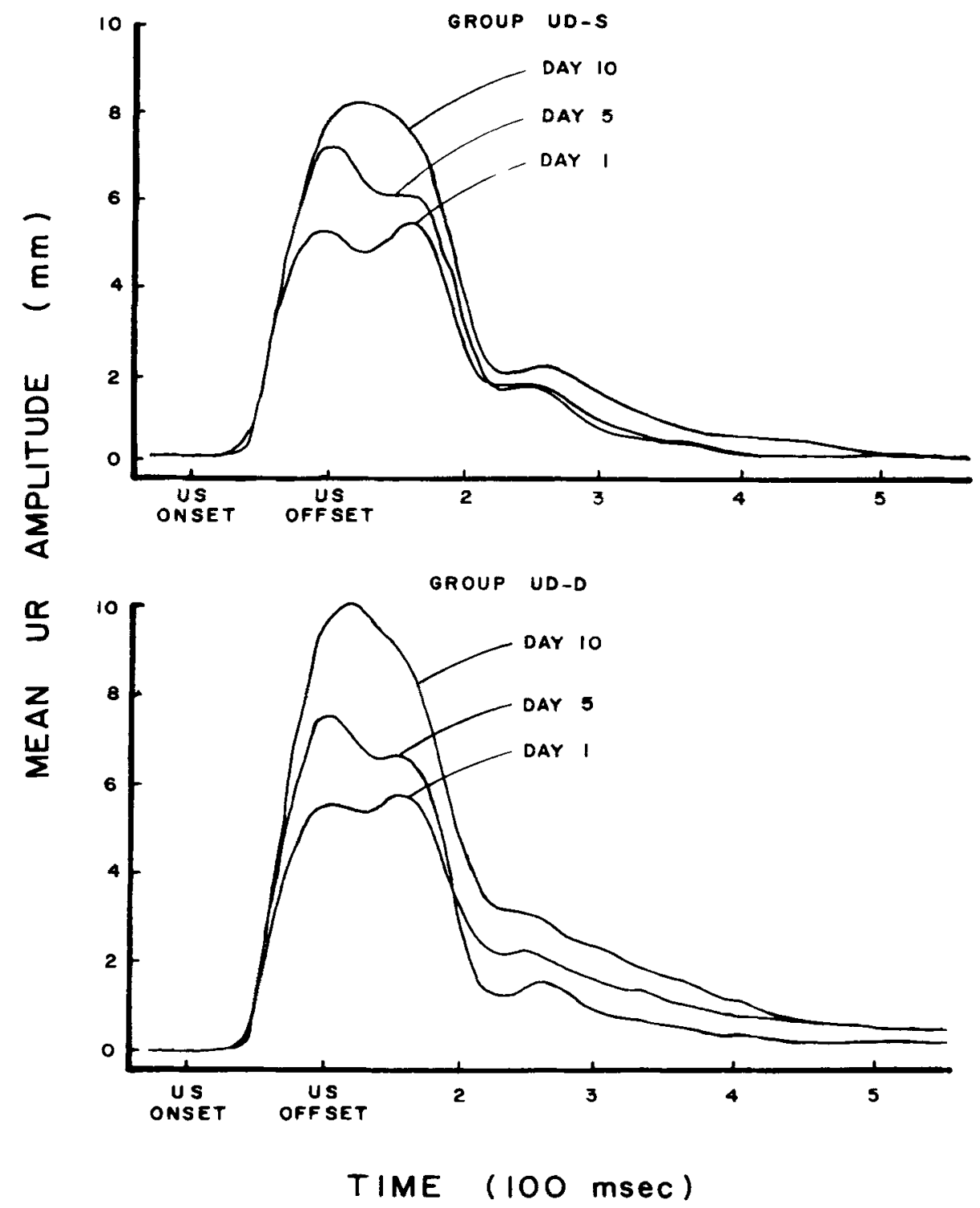

Figure 4. The mean UR topography for Groups UD-S (top frame) and UD-D (bottom frame) on Days 1,5 , and 10 of the US preexposure phase. The time base is initialized at US onset.

levels. Moreover, Group UD-S seemed to exhibit a slower rate of acquisition than did Groups UD-D, D, and E, which did not appear to differ from each other. The variations in group performance on $\mathrm{CS}^{+}$trials was confirmed by a significant day $\times$ group interaction $[F(18,252)=$ $2.50, p<.01]$, which contained only a significant quadratic component for trend $[F(3,252)=11.15, p<.01]$. The quadratic component resulted from significant quadratic components over days for Groups UD-D, D, and $\mathrm{E}\left[F_{\mathrm{S}}(1,252)=28.68,45.89\right.$, and 20.57 , respectively; $p$ s $<.01]$ but not for Group UD-S $[F(1,252)<1.0]$. Since quadratic trends are obtained only after several days of asymptotic performance, the absence of a quadratic trend for Group UD-S indicates that Group UD-S reached asymptote values later than did the other groups. Figure 5 also shows that, on $\mathrm{CS}^{-}$trials, the percentage of responding for both Groups UD-D and D evidenced a gradual increase to a low asymptotic level, whereas the responding for Groups UD-S and E was similar and did not systematically change over days. The ANOVA yielded a significant day $\times$ group interaction $[F(18,252)=2.70$, $p<.05]$, which contained a significant linear orthogonal trend component $[F(3,252)=7.02, p<.01]$. Orthogonal components for trend applied to each group identified significant increasing linear components for Groups UD-D and $\mathrm{D}[F(1,252)=28.71, p<.01$, and $F(1,252)=34.41, p<.01$, respectively] but not Groups UD-S and $E[F(1,252)=3.80$ and $F(1,252)<1.0$, 


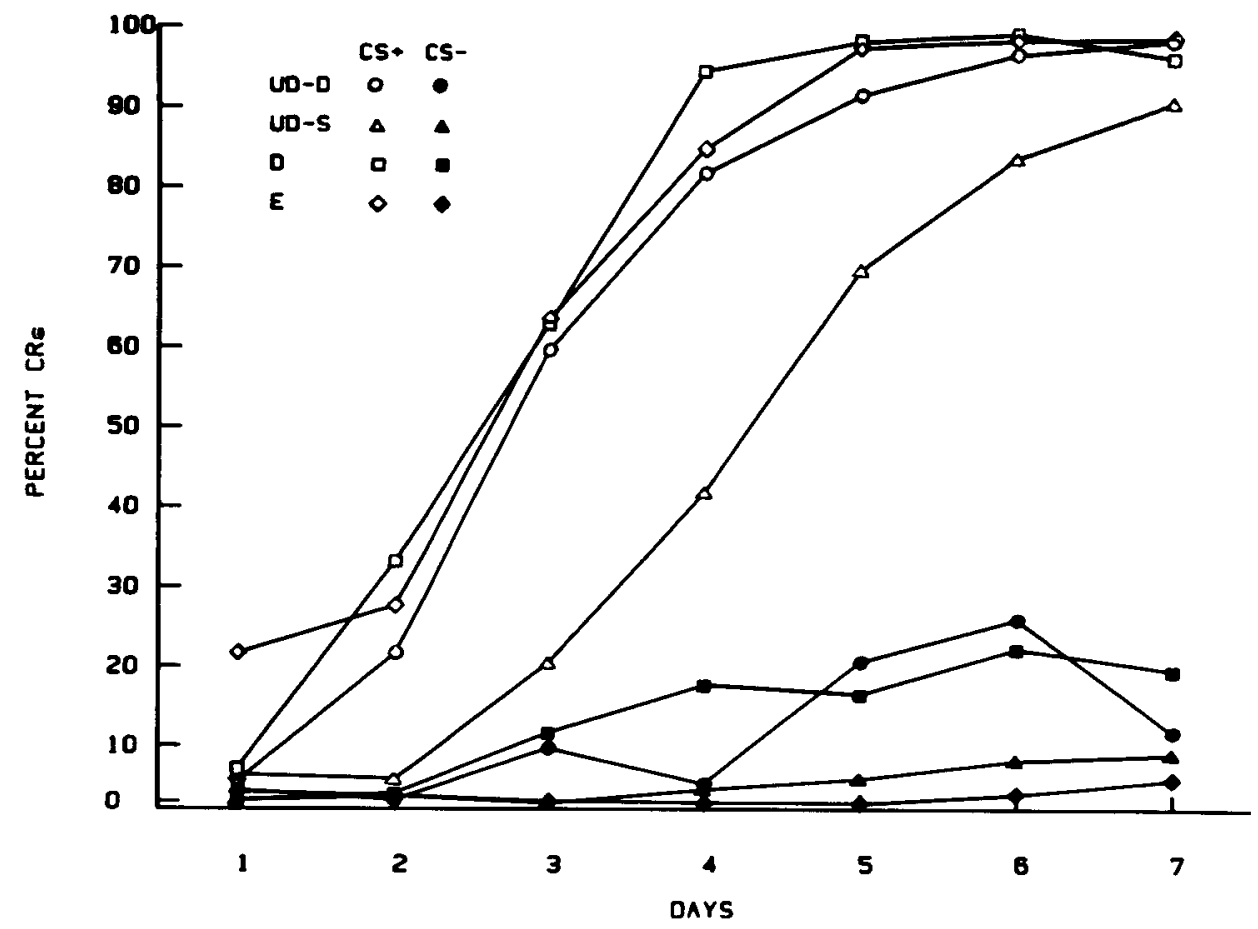

Figure 5. The mean daily percentages of CRs to $\mathrm{CS}^{+}$and $\mathrm{CS}^{-}$for Groups UD-D, UD-S, D, and $E$ as a function of the 7 days of differential conditioning.

respectively]. Since Group E provided an index of baseline responding, it appeared that Group UD-S responded at or near baseline levels.

Retardation of learning test. The mean percentage of CRs on the retardation of learning test for Groups UD-S, UD-D, D, and E were 60.4, 72.8, 76.6, and 94.6, respectively. An ANOVA applied to the inhibition test data revealed a significant group main effect $[F(3,42)=10.17$, $p<.01]$. The Newman-Keuls test identified that Group UD-S had a lower percentage of responding than each of the other groups, and that Groups UD-D and D, which did not differ from one another, exhibited a lower level of responding than Group E. The results show that associative inhibition was present in Groups UD-S, UD$\mathrm{D}$, and $\mathrm{D}$, and that the development of inhibition was accelerated by US preexposure in the same context, but not if the US preexposures occurred in a different context.

Figure 6 depicts the mean percentage of CRs for all groups as a function of days of the retardation of learning inhibition test. The figure shows that on Day 1 the percentage of CRs was low for Group UD-S and was very high for Group E; the percentages of CRs for Groups UD$\mathrm{D}$ and $\mathrm{D}$ were between the two extremes. Over days, all groups converged on a high terminal value. The ANOVA revealed a significant day $\times$ group interaction $[F(6,84)$ $=7.11, p<.01]$, which contained a significant linear component for trend $[F(3,84)=13.23, p<.01]$ that confirmed the convergence of the groups. Although all groups had significant linear components over days, the groups with the steeper slopes contributed a higher propor- tion of variance to the linear interaction $(42.0 \%, 33.9 \%$, $23.1 \%$, and $1.0 \%$ for Groups UD-S, UD-D, D, and E, respectively).

Group UD-S of Experiment 2 replicated the effects of US preexposure observed in Experiment 1 . For Group UD-S, acquisition to $\mathrm{CS}^{+}$was slower than it was for controls, responding to $\mathrm{CS}^{-}$was at baseline levels, and acquisition on the retardation of learning test for inhibition was more retarded than it was for nonpreexposed differentially conditioned rabbits. Thus, US preexposures again produced the conjoint effects of retardation of excitatory and facilitation of inhibitory conditioning. Moreover, since Group UD-D, the group that had received a shift in context after the US preexposure phase, failed to differ from the nonpreexposed Group D on $\mathrm{CS}^{+}$ and $\mathrm{CS}^{-}$trials and on the inhibition test, Experiment 2 indicated that both the retardation and facilitation effects were context specific.

\section{GENERAL DISCUSSION}

Although current theoretical models of US preexposure effects readily account for the retardation observed in the acquisition to $\mathrm{CS}^{+}$, our confirmation of Hinson's (1982, Experiment 4) finding that US preexposures facilitate inhibitory conditioning challenges the tenability of adaptational (e.g., Taylor, 1956) and cognitive (Baker et al., 1981; Mackintosh, 1973, 1975; Maier \& Seligman, 1976) accounts. Both positions assert that the capacity of a US to reinforce learning to CSs is degraded by US preex- 


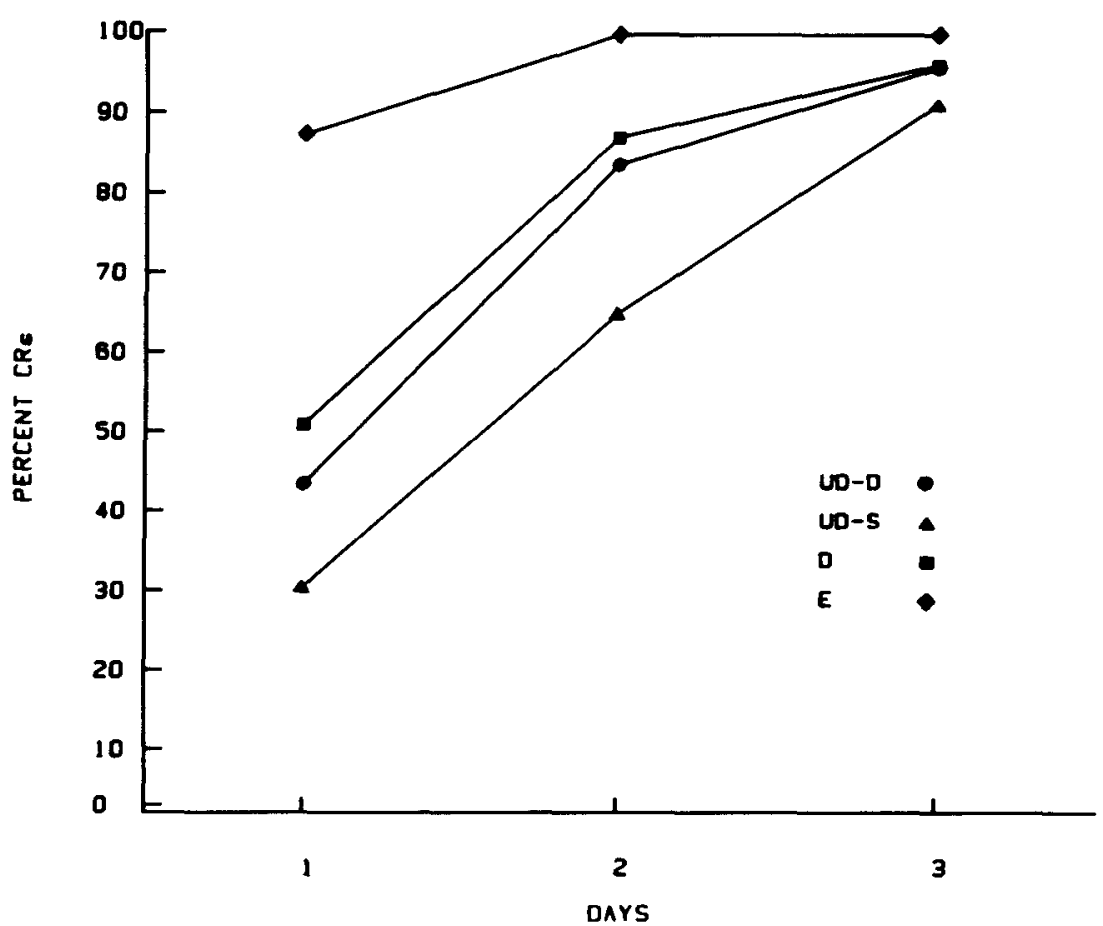

Figure 6. The mean daily percentages of CRs during the 3-day retardation of learning test of inhibition for Groups UD-D, UD-S, D, and E.

posures. With a less effective US, neither excitatory nor inhibitory conditioning should be facilitated. Consequently, the observation of enhanced inhibitory conditioning following US preexposures is directly contrary to the theoretical expectations.

Opponent-process models (LoLordo \& Randich, 1981; Solomon \& Corbit, 1974) fair slightly better under the present results. The observation of the simultaneous occurrence of retarded excitatory and facilitated inhibitory conditioning would be assumed to reflect the growth of the endogenous hedonically opposite process of the US during the US preexposure phase. As a consequence, the capacity of the US to support excitatory conditioning would be diminished because the effectiveness of the US is determined by the temporal integration of the two hedonically opposite processes. Moreover, because the hedonically opposite process is assumed to decay slowly over some unspecified time period, and because inhibition may result from pairing a CS with the hedonic opposite of the US, inhibitory conditioning would be facilitated after the creation of a strong hedonic opposite by US preexposures. In the present experiments, it would only have to be assumed that the hedonic opposite process extended through the intertrial interval to the point in time of $\mathrm{CS}^{-}$occurrence to account for the obtained facilitated inhibition.

However, the opponent-process models encounter difficulties with two of the present observations. First, the models propose that the US preexposure effects are a result of a change in the dynamic consequences of the US, and therefore, only changes in US parameters should regulate the US preexposure effects. A change in ex- perimental environment between the US preexposure phase and the conditioning phase should not affect the postulated mechanism. However, contrary to theoretical expectations, the context shift manipulation in Experiment 2 removed both the retardation and facilitation effects of US preexposure. Second, opponent process models assume that the hedonic opposite process increases in strength as a function of the number of US preexposures. As a consequence, the net hedonic consequence of the US, which reflects the temporal integration of the two hedonic processes, is reduced. This should make the US a less effective excitatory stimulus. To the extent that URs index the net hedonic consequence of the US (Solomon \& Corbit, 1974), URs should decrease in amplitude as a function of days of US preexposures. Although recording equipment constraints precluded a trial-by-trial analysis of peak UR amplitude, we were able to tabulate the daily mean peak UR amplitude for each subject. Both Experiment 1 and Experiment 2 replicated the previous observation (Mis \& Moore, 1973; Suboski, Di Lollo, \& Gormezano, 1964) that UR amplitude increased over preexposure days. The increase in UR amplitude could be interpreted to suggest that the net excitatory hedonic consequence of the US increased rather than decreased over days of US preexposures. Thus, opponent-process models appear to be inadequate because they lack an explanatory vehicle to explain the context shift outcome and incorrectly predict the effects of US preexposure on URs.

Of the current theories, the context blocking (Randich \& LoLordo, 1979; Tomie et al., 1980) and scalar expectancy (Gibbon \& Balsam, 1981) associative theories give 
the most inclusive account of the present outcomes. Both positions assert that associations between the context and the US are established during US preexposures. Subsequently, the context-US association interferes with the development of a CS-US association (context blocking) or performance to the discrete CS (scalar expectancy), but facilitates the development of inhibition to a discrete CS by providing an excitatory contrast for that CS. Since the explanatory mechanism for US preexposure effects requires the presence of the same context for the preexposure and conditioning phases, a context shift inserted between the phases should remove the effectiveness of the US preexposures. Thus, both theories accurately predict the effects observed with the context shift in Experiment 2.

Although the context blocking and scalar expectancy theories adequately account for the major observations of the present studies, there are some US preexposure effects that are not consistent with these theories. First, since the associative theories assert that common mechanisms underlie CS-US and context-US associations, behavioral changes during CS-US conditioning should also occur during context-US conditioning. One observation from discrete cue conditioning is that UR amplitude decreases when the CS acquires an excitatory association (Donegan, 1981; Kimmel, 1966; Terry, 1976; Terry \& Wagner, 1975; but see Desmond, Romano, \& Moore, 1980; Hupka, Kwaterski, \& Moore, 1970). Presumably, the UR diminution results because the expected US is less surprising (Kamin, 1968) or needs less rehearsal (Wagner, 1981). Whatever the mechanism, the associative theories of US preexposure effects would expect a parallel behavioral observation as the subject learns to expect the US in a context. Therefore, UR diminution should be observed during US preexposures. However, UR enhancement is found over days of US preexposures (Experiments 1 and 2; Mis \& Moore, 1973; Suboski et al., 1964).

Second, if previously conditioned contextual associations interfere with excitatory conditioning, then indices of contextual conditioning should be correlated with the subsequent occurrence of retarded excitatory conditioning. Such correlations are not always observed (e.g., Ayres, Bombace, Shurtleff, \& Vigorito, 1985). The problem is exacerbated by the fact that contextual conditioning, at least with aversive USs, occurs rapidly (cf. Marlin, 1983; McAllister \& McAllister, 1971) and can summate with discrete cue conditioning (Balaz, Capra, Hartl, \& Miller, 1981; McAllister \& McAllister, 1971). In contrast, to produce retarded acquisition with US preexposures requires extensive US preexposure training (e.g., the 10 days and 200 US presentations employed in the present study), with the training period usually being longer than the amount of training needed to produce subsequent asymptotic conditioning of the response system of interest. Since contextual conditioning can occur rapidly, extensive training with the US should not be needed to produce the US preexposure effects. The observations of different temporal courses for contextual conditioning and US preexposure effects and the occurrence of US preexposure effects in the absence of evidence for contextual conditioning (Ayres et al., 1985) are inconsistent with the associative theories of US preexposure effects.

An alternative associative account can be generated from slightly different assumptions concerning the effects of US preexposure. During the US preexposure phase, brief US presentations are interposed between long intervals of non-US presentations. Although this would lead to initial excitatory contextual conditioning effects, it also would establish the conditions needed for the formation of a temporal discrimination. With extended training, nonUS periods should become inhibitory. Since the non-US periods are substantially longer than the US periods, the resultant effect would be to leave the context with a net inhibitory associative strength.

If the context were associatively inhibitory, then the following outcomes could be expected. First, the introduction of forward pairings should show retarded acquisition, since the excitatory effects to the CS would have to be larger than the concurrent inhibitory effects of the context before CR performance would be observed. Since the $\mathrm{CS}^{+}$is being paired within the inhibitory context, the conditions for the occurrence of superconditioning (Rescorla, 1971) exist. Thus, although performance to the $\mathrm{CS}^{+}$ during differential conditioning should be retarded after US preexposure, associative strength should accrue more rapidly to the $\mathrm{CS}^{+}$in the preexposed condition than in a nonpreexposed condition. To test this novel prediction, the associative strength of the $\mathrm{CS}^{+}$would have to be evaluated in the absence of the inhibitory contextual stimuli (i.e., in an environment in which US preexposures had not been delivered). Second, with backward pairings or differential conditioning, the inhibition that accrues to the CS would be augmented by higher order inhibitory pairings between the context and the CS (cf. Baker, 1974, for results that suggest that inhibitory CSs can support higher order conditioning). Thus, the CSs would become more inhibitory than CSs that do not follow US preexposure. Third, since the development of the inhibitory context is an associative outcome, a shift in context between the US preexposure and the discrete cue acquisition phases should remove the effects of preexposure on subsequent excitatory and inhibitory conditioning. Fourth, since UR amplitude is enhanced when a $\mathrm{CS}^{-}$signals a US (Donegan, 1981; Desmond et al., 1980), a gradual increase in UR amplitude could result as the context becomes inhibitory, since the expectation of the US would decrease and, therefore, when the US occurs, it should be more surprising (Kamin, 1968) or its rehearsal be increased (Wagner, 1981).

And finally, if the associative strength of the context passes from a net excitatory to a net inhibitory associative strength, then the different time courses for the indices of contextual conditioning and US preexposure effects would be resolved. A postulated early excitatory phase would account for rapid contextual conditioning. If an assumption of summative associative interactions be- 
tween the context and a CS is made (Balaz et al., 1981; McAllister \& McAllister, 1971), then the facilitative effects of brief US preexposure training (e.g., LoLordo \& Randich, 1981) on discrete cue acquisition would be expected. The slow development of an inhibitory context would account for the extensive training needed to produce subsequent retarded excitatory and facilitated inhibitory conditioning. If an inhibitory context is influencing performance in subsequent discrete cue conditioning, then the training needed to create the net inhibitory effect would be the limiting process on the demonstration of US preexposure effects.

\section{REFERENCES}

Ayres, J. J. B., Bombace, J. C., ShurtlefF, D., \& Vigorito, M. (1985). Conditioned suppression tests of the context-blocking hypothesis: Testing in the absence of the preconditioned context. Journal of Experimental Psychology: Animal Behavior Processes, 11, 1-14.

BAKER, A. G. (1974). Conditioned inhibition is not the symmetrical opposite of conditioned excitation: A test of the Rescorla-Wagner model. Learning \& Motivation, 5, 369-379.

BAKer, A. G., \& Mercier, P. (1982). Manipulation of the apparatus and response context may reduce the US pre-exposure interference effect. Quarterly Journal of Experimental Psychology, 34B, 221-234.

Baker, A. G., Mercier, P., Gabel, J., \& Baker, P. A. (1981). Contextual conditioning and the US preexposure effect in conditioned fear. Journal of Experimental Psychology: Animal Behavior Processes, 7 , 109-128.

Balaz, M. A., Capra, S., Harte, P., Miller, R. R. (1981). Contextual potentiation of acquired behavior after devaluing direct contextUS associations. Learning \& Motivation, 12, 383-397.

Desmond, J. E., Romano, A. G., \& MoOre, J. W. (1980). Amplitude of the rabbit's unconditioned nictitating membrane response in the presence of a conditioned inhibitor. Animal Learning \& Behavior, 8, 225-230.

Donegan, N. H. (1981). Priming-produced facilitation or diminution of responding to a Pavlovian unconditioned stimulus. Journal of Experimental Psychology: Animal Behavior Processes, 7, 295-312.

Gibbon, J., \& Balsam, P. (1981). Spreading association in time. In C. M. Locurto, H. S. Terrace, \& J. Gibbon (Eds.), Autoshaping and conditioning theory. New York: Academic Press.

Gormezano, I. (1966). Classical conditioning. In J. B. Sidowski (Ed.), Experimental methods and instrumentation in psychology. New York: McGraw-Hill.

HINSON, R. E. (1982). Effects of UCS preexposure on excitatory and inhibitory rabbit eyelid conditioning: An associative effect of conditioned contextual stimuli. Joumal of Experimental Psychology: Animal Behavior Processes, 8, 49-61.

Hupka, R. B., Kwaterski, S. E., \& Moore, J. W. (1970). Conditioned diminution of the UCR: Differences between the human eyeblink and the rabbit's nictitating membrane response. Journal of Experimental Psychology, 83, 45-51.

KAMIN, L. J. (1968). Attention-like processes in classical conditioning. In M. R. Jones (Ed.), Miami symposium on the prediction of behavior: Aversive stimulation. Miami: University of Miami Press.

Kamin, L. J. (1969). Predictability, surprise, attention and conditioning. In B. A. Campbell \& R. M. Church (Eds.), Punishment and aversive behavior. New York: Appleton.

KIMMEL, H. D. (1966). Inhibition of the unconditioned response in classical conditioning. Psychological Review, 73, 232-240.

LoLORDO, V. M., \& RANDICH, A. (1981). Effects of experience of electric shock upon subsequent conditioning of an emotional response: Associative and non-associative accounts. In P. Harzen \& M. D. Zeiler (Eds.), Advances in analysis of behavior: Predictability, correlation, and contiguity (Vol. 2). New York: Wiley.
Macdonald, A. (1946). The effects of adaptation to the unconditioned stimulus upon the formation of conditioned avoidance responses. Journal of Experimental Psychology, 36, 1-12.

Mackintosh, N. J. (1973). Stimulus selection: Learning to ignore stimuli that predict no change in reinforcement. In R. A. Hinde \& J. Stevenson-Hinde (Eds.), Constraints on learning. London: Academic Press.

MACKINTOSH, N. J. (1975). A theory of attention: Variations in the associability of stimuli with reinforcement. Psychological Review, 82 276-298.

Maier, S. F., \& Seligman, M. E. P. (1976). Learned helplessness: Theory and evidence. Journal of Experimental Psychology: General, 105, 3-46.

MARLIN, N. A. (1983). Second-order conditioning using a contextual stimulus as $\mathrm{S}_{1}$. Animal Learning \& Behavior, 11, 290-294.

MCAllister, W. R., \& MCAllister, D. E. (1971). Behavioral measurement of conditioned fear. In F. R. Brush (Ed.), Aversive conditioning and learning. New York: Academic Press.

Mis, R. W., Moore, J. W. (1973). Effects of preacquisition UCS exposure on classical conditioning of the rabbit's nictitating membrane response. Learning \& Motivation, 4, 108-114.

MOORE, J. W. (1972). Stimulus control: Studies of auditory generalization in rabbits. In A. H. Black \& W. F. Prokasy (Eds.), Classical conditioning: II. Current theory and research. New York: AppletonCentury-Crofts.

Pavlov, I. P. (1927). Conditioned reflexes. New York: Dover.

QUESNEL, L. J. (1983). Classical aversive conditioning of the rabbit's leg flexion response. Unpublished MA thesis, University of Manitoba.

RANDICH, A., LoLoRDo, V. M. (1979). Associative and nonassociative theories of the UCS preexposure phenomenon: Implications for Pavlovian conditioning. Psychological Bulletin, 86, 523-548.

Reberg, D., B Black, A. H. (1969). Compound testing of individually conditioned stimuli as an index of excitatory and inhibitory properties. Psychonomic Science, 17, 30-31.

Rescorla, R. A. (1971). Variations in the effectiveness of reinforcement and nonreinforcement following prior inhibitory conditioning. Learning \& Motivation, 2, 113-123.

Rescorla, R. A., \& Wagner, A. R. (1972). A theory of Pavlovian conditioning: Variations in the effectiveness of reinforcement and nonreinforcement. In A. H. Black \& W. F. Prokasy (Eds.), Classical conditioning: II. Current theory and research. New York: AppletonCentury-Crofts.

SIEGEL, S., \& DomJaN, M. (1971). Backward conditioning as an inhibitory training procedure. Learning \& Motivation, 2, 1-11.

Solomon, R. L., C CoRBIT, J. D. (1974). An opponent-process theory of motivation: I. Temporal dynamics of affect. Psychological Review, $81,119-145$.

Suboski, M. D., Di Lollo, V., \& Gormezano, I. (1964). Effects of unpaired pre-acquisition exposure of CS and US on classical conditioning of the nictitating membrane response of the albino rabbit. Psychological Reports, 15, 571-576.

TAIT, R. W., \& GoRMEzano, I. (1974). A microcomputer program for stimulus control and analog data for discrete trials paradigm in biological preparation: Classical conditioning. Behavior Research Methods \& Instrumentation, 6, 295-300.

TAYLOR, J. A. (1956). Level of conditioning and the intensity of the adaptation stimulus. Joumal of Experimental Psychology, 51, 127-130.

TERRY, W. S. (1976). Effects of priming unconditioned stimulus representations in short-term memory on Pavlovian conditioning. Journal of Experimental Psychology: Animal Behavior Processes, 2, 354-369.

TERRY, W. S., \& WAGNER, A. R. (1975). Short-term memory for "surprising" vs. "expected" unconditioned stimuli in Pavlovian conditioning. Journal of Experimental Psychology: Animal Behavior Processes, 1, 122-133.

Tomie, A. (1976). Retardation of autoshaping: Control by contextual stimuli. Science, 192, 1244-1245.

Tomie, A., Murphy, A. L., FATH, S., \& JACKson, R. L. (1980). Retardation of autoshaping following pretraining with unpredictable 
food: Effects of changing the context between pretraining and testing. Learning \& Motivation, 11, 117-134.

WAGNER, A. R. (1981). SOP: A model of automatic memory processing in animal behavior. In N. E. Spear \& R. R. Miller (Eds.), Information processing in animals: Memory mechanisms. Hillsdale, $\mathrm{NJ}$ : Erlbaum.

WAgner, A. R., \& ResCoRlA, R. A. (1972). Inhibition in Pavlovian conditioning: Application of a theory. In R. A. Boakes \& M. S. Halliday (Eds.), Inhibition and learning. London: Academic Press.

Wessels, M. G. (1973). Errorless discrimination, autoshaping and conditioned inhibition. Science, 182, 941-943.

Williams, D. A., \& TAIT, R. W. (1983, June). Associative inhibition:
A failure of the Rescorla-Wagner model. Poster presented at the Canadian Psychological Association Annual Convention, Winnipeg, Manitoba.

WiLLNER, J. A. (1978). Blocking of a taste aversion by prior pairings of exteroceptive stimuli with illness. Learning \& Motivation, 9, 125-140.

(Manuscript received September 26, 1985; revision accepted for publication March 3, 1986.) 